\title{
Right Anterior Apical Transition Zone of Prostate
}

National Cancer Institute

\section{Source}

National Cancer Institute. Right Anterior Apical Transition Zone of Prostate. NCI

Thesaurus. Code C128584.

The region of the prostate that is located on the anatomical right side of the anterior portion of the apical division of the transition zone. 